\title{
Aberrations of biochemical indicators in amyotrophic lateral sclerosis: a systematic review and meta-analysis
}

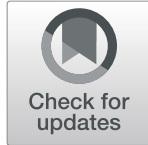

\author{
Yangfan Cheng ${ }^{1,2}$, Yongping Chen ${ }^{1,2}$ and Huifang Shang ${ }^{1,2^{*}}$ (D)
}

\begin{abstract}
Accumulating evidence has suggested that the pathological changes in amyotrophic lateral sclerosis (ALS) are not only confined to the central nervous system but also occur in the peripheral circulating system. Here, we performed a meta-analysis based on the PubMed, EMBASE, EBSCO, and CNKI databases, to find out biochemical indicators associated with energy metabolism, iron homeostasis, and muscle injury that are altered in ALS patients and their correlations with ALS phenotypes. Forty-six studies covering 17 biochemical indicators, representing 5454 ALS patients and 7986 control subjects, were included in this meta-analysis. Four indicators, including fasting blood glucose level (weighted mean difference $[\mathrm{WMD}]=0.13,95 \% \mathrm{Cl}[0.06-0.21], p=0.001)$, serum ferritin level $(\mathrm{WMD}=$ 63.42, 95\% Cl [48.12-78.73], $p<0.001)$, transferrin saturation coefficient level (WMD $=2.79,95 \% \mathrm{Cl}[1.52-4.05], p<$ 0.001), and creatine kinase level (WMD $=80.29,95 \% \mathrm{Cl}$ [32.90-127.67], $p<0.001)$, were significantly higher in the ALS patients, whereas the total iron-binding capacity (WMD $=-2.42,95 \% \mathrm{Cl}[-3.93,-0.90], p=0.002$ ) was significantly lower in ALS patients than in the control subjects. In contrast, the other 12 candidates did not show significant differences between ALS patients and controls. Moreover, pooled hazard ratios (HR) showed significantly reduced survival $(H R=1.38,95 \% \mathrm{Cl}[1.02-1.88], p=0.039)$ of ALS patients with elevated serum ferritin levels. These findings suggest that abnormalities in energy metabolism and disruption of iron homeostasis are involved in the pathogenesis of ALS. In addition, the serum ferritin level is negatively associated with the overall survival of ALS patients.
\end{abstract}

Keywords: Amyotrophic lateral sclerosis, Biochemical indicators, Energy homeostasis, Iron metabolism, Creatinine kinase

\section{Background}

Amyotrophic lateral sclerosis (ALS) is a relentlessly progressive paralytic disease characterized by degeneration of upper and lower motor neurons, which occurs following insidious focal weakness and spreads to most skeletal muscles, including the diaphragm $[1,2]$. To date, there is no curative treatment for ALS and most patients die

\footnotetext{
*Correspondence: hfshang2002@126.com

'Department of Neurology, Laboratory of Neurodegenerative Disorders, Rare Disease Center, West China Hospital, Sichuan University, Chengdu 610041, China

${ }^{2}$ National Clinical Research Center for Geriatric, Laboratory of Neurodegenerative Disorders, West China Hospital, Sichuan University, Chengdu 610041, China
}

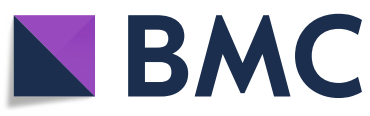

(C) The Author(s). 2021 Open Access This article is licensed under a Creative Commons Attribution 4.0 International License, which permits use, sharing, adaptation, distribution and reproduction in any medium or format, as long as you give appropriate credit to the original author(s) and the source, provide a link to the Creative Commons licence, and indicate if changes were made. The images or other third party material in this article are included in the article's Creative Commons licence, unless indicated otherwise in a credit line to the material. If material is not included in the article's Creative Commons licence and your intended use is not permitted by statutory regulation or exceeds the permitted use, you will need to obtain permission directly from the copyright holder. To view a copy of this licence, visit http://creativecommons.org/licenses/by/4.0/ The Creative Commons Public Domain Dedication waiver (http://creativecommons.org/publicdomain/zero/1.0/) applies to the data made available in this article, unless otherwise stated in a credit line to the data. within 5 years of disease onset due to respiratory paralysis [3]. The ALS etiology is unfortunately poorly understood.

A recent epidemiological study has shown that the mean age for typical ALS disease onset is $61.8 \pm 3.8$ years [4], whereas the diagnosis of ALS has been reported to be delayed for over 1 year due to the significant overlap of clinical manifestations with other conditions in the early stages of ALS [5]. Therefore, exploring robust biomarkers is essential for the diagnosis of ALS. Biochemical indices in the blood or cerebrospinal fluid (CSF) are readily available compared to the brain tissue; they are regarded as indicators, and may 
also be involved in the development of disease, thus having been studied widely. Accumulating evidence has suggested that some indicators associated with energy homeostasis, including glucose [6-8], lipid [9-11] and protein levels [12-14], are aberrant in ALS patients. Moreover, abnormal iron metabolism [15-17] and creatinine kinase [18-20] have been reported in ALS patients. However, these studies have not reached a consensus; thus, a systematic meta-analysis is needed to clarify the changes in biochemical indicators in ALS and make a better prognosis.

In this review, we set out to go over the literature to examine if the commonly reported clinical biochemical indicators, which include total cholesterol (TC), lowdensity lipoprotein (LDL), high-density lipoprotein (HDL), triglyceride (TG), fasting blood glucose (FBG), fasting insulin, glucose in CSF, total protein in CSF, CSF/serum albumin quotient (Qalb), serum albumin, serum total protein, ferritin, transferrin, iron, total ironbinding capacity (TIBC), transferrin saturation coefficient (TSC), and creatine kinase (CK), are aberrant in ALS patients, and analyze their associations with patient survival.

\section{Methods}

\section{Literature search strategy and selection criteria}

Systematic review and meta-analysis was performed according to the Preferred Reporting Items for Systematic Review and Meta-Analyses guidelines [21]. The PubMed, EMBASE, EBSCO and CNKI databases were systematically searched until January 2020, using search terms of "amyotrophic lateral sclerosis OR ALS OR Lou Gehrig's disease" AND "cholesterol OR triglycerides OR lipid" for lipid metabolism, "fasting glucose OR blood glucose OR blood sugar OR glycated hemoglobin A OR HbA1c OR hyperglycemia OR hypoglycemia OR glycemic index" for glycometabolism, "albumin OR prealbumin OR prealbumin OR globulin" for protein metabolism, "ferritin OR transferrin OR iron" for iron metabolism, and "creatine kinase OR CK" for muscle injury. All papers were reviewed for titles and abstracts. References of the relevant articles were also reviewed to identify eligible articles.

The inclusion criteria for eligible articles were as follows: (1) written in English or Chinese; (2) providing definite diagnostic criteria for ALS patients; (3) being a case-control study or a cohort study; (4) the control group included healthy controls or several other neurological disorders (ONDs); and (5) reporting quantitative values of blood biochemical indicators in case-control studies, hazard ratio (HR) with 95\% confidence interval (CI), or figures or tables of survival analyses. The exclusion criteria were as follows: (1) studies in animals or cell lines; (2) duplicate reports or different papers sharing the same cohort; and (3) reviews, case reports, editorials, and abstracts for conferences.

\section{Data extraction}

For each study included, the following items were extracted: publication year, author name, location of the trial, sample size, age and sex of participants (ALSs and controls), and case ascertainment. Furthermore, the mean and standard deviation (SD) of levels of biochemical indicators, and HR with $95 \% \mathrm{CI}$ were also extracted. Data presented in different units or other expression forms were converted to conform to the requirements $[22,23]$.

\section{Statistical analysis}

The mean and SD of biochemical indicator concentrations were used to generate the effect size (ES) calculated as the weighted mean difference (WMD), to compare the differences between ALS patients and controls. To eliminate the bias from healthy/disease control and demographics of the study populations, separate analyses were carried out to examine the findings more carefully. We used a pooled HR with $95 \%$ CI to evaluate the association of blood biochemical indicators that show significant difference between ALS patients and controls, with survival time. For papers that provided Kaplan-Meier survival analyses, we transformed the figure into a data sheet and used the log rank test to obtain the HR and 95\% CI [24]. The $I^{2}$ statistic and Cochrane $\mathrm{Q}$ test were used to analyze between-study heterogeneity [25]. If $I^{2}<50 \%$ and $p>0.1$ in the Q test, which means no obvious heterogeneity, the fixed-effects model was used to calculate the pooled estimate. Otherwise, the random-effects model was used for data with substantial heterogeneity. Subgroup analysis and meta-regression were conducted to explore potential sources of heterogeneity. Publication bias was determined using the Egger test, as described previously [26]. To evaluate the stability, we also performed sensitivity analysis by omitting each study in turn. All data were analyzed using STATA (version 15.0) software. $p<0.05$ was considered statistically significant.

\section{Results}

\section{Characteristics of the included studies}

As shown in Fig. 1, a systematic review of the literature identified 2803 papers from online databases. After screening titles and abstracts of these papers, 2482 papers were excluded, and 321 papers were further evaluated via a full-text review. After excluding articles without valid data, review articles, meta-analyses and case reports, 46 original articles were finally selected for the meta-analysis, which covered a total of 17 biochemical indicators in the serum or CSF in 5454 ALS patients 


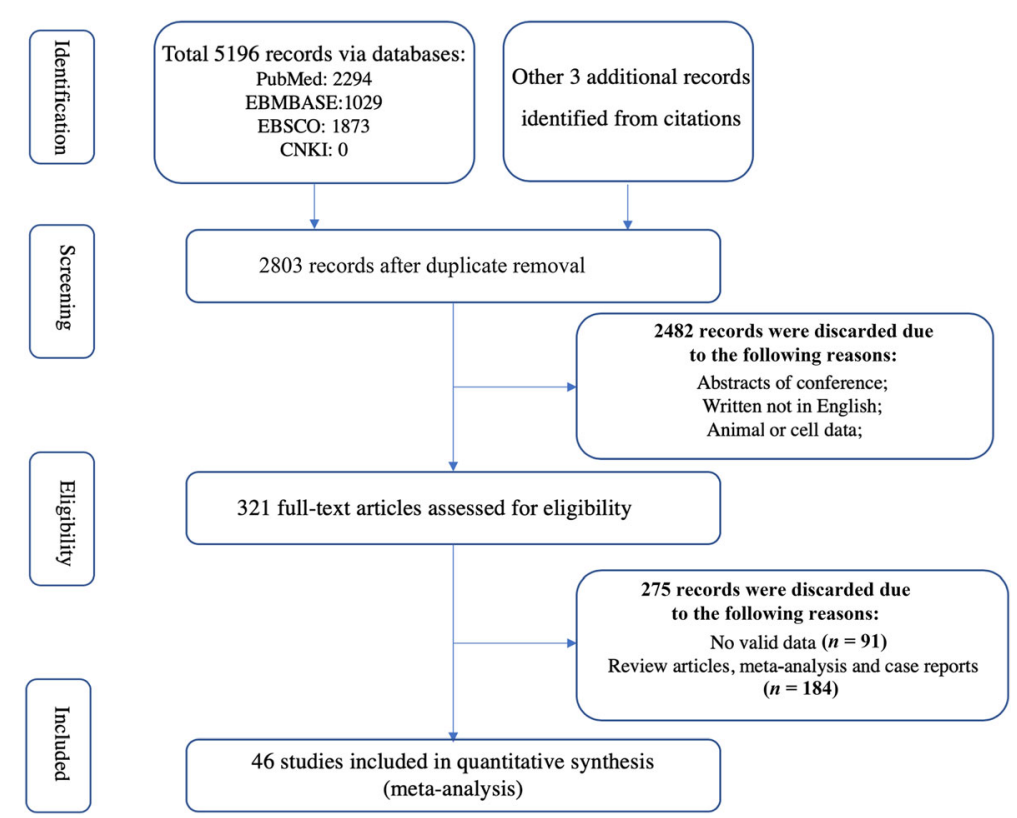

Fig. 1 Flowchart of the literature search according to Preferred Reporting Items for Systematic Review and Meta-Analyses

and 7986 controls $[8,13,16-18,27-67]$. Table S1 shows the characteristics of each study.

\section{Quantitative synthesis}

As shown in the forest plot (Fig. 2), fixed-effects metaanalysis was performed to compare the FBG, TIBC, and TSC between ALS patients and controls, whereas for serum ferritin and CK, we applied a random-effects model. The levels of FBG (WMD $=0.13$, 95\% CI $[0.06-$ $0.21], p=0.001$ ), serum ferritin (WMD $=63.42,95 \% \mathrm{CI}$ [48.12-78.73], $p<0.001)$, TSC (WMD $=2.79,95 \%$ CI [1.52-4.05], $p<0.001)$, and CK (WMD $=80.29,95 \%$ CI [32.90-127.67], $p<0.001)$ were significantly higher in the ALS patients, whereas TIBC (WMD $=-2.42,95 \%$ CI $[-3.93,-0.90], p=0.002$ ) was significantly lower in the ALS patients, compared to the controls (Table 1). In contrast, no significant difference was found in lipid metabolism markers including TC, HDL-C, LDL-C, and TG, fasting serum insulin, serum albumin, serum total protein, serum transferrin, serum iron, CSF glucose, CSF total protein and Qalb. Considering that some ONDs per se are associated with peripheral biochemical changes, we conducted a separate analysis based on the control group to confirm our findings (Table 2). The serum transferrin level was significantly lower in ALS patients than in healthy controls (WMD $=-0.13,95 \%$ CI $[-0.17,-0.08], p<0.001)$ but not significantly different from that in patients with ONDs (WMD $=0.81,95 \%$ CI $[-1.34,2.96], p=0.46$ ) (Fig. 3a). Furthermore, by performing a separate analysis based on ethnicity, we found ethnographic heterogeneity on HDL-C between patients with ALS and controls. HDL-C was lower in ALS patients in Asia (WMD $=-3.06,95 \%$ CI $[-5.99$, $-0.13], p=0.041)$, but was significantly higher in the USA (WMD $=13.87,95 \%$ CI [6.93-20.82], $p<0.001$ ) and European studies (WMD $=3.11,95 \%$ CI $[0.20$ 6.01], $p=0.036$ ) (Fig. 3b). Separate analyses of other indicators based on ethnicity are shown in Figure S1.

\section{Investigation of heterogeneity}

The heterogeneity analysis showed that the FBG, total protein and glucose in CSF, TIBC, and TSC\% did not show heterogeneity among studies, while Qalb, serum ferritin, and serum iron presented substantial betweenstudy heterogeneity, whereas evident heterogeneity among studies was shown for TC, LDL-C, HDL-C, TG, fasting insulin, serum albumin, serum total protein, serum transferrin, and CK (Table 1).

We then explored if there were potential variables that could explain the heterogeneity. As two indicators (serum ferritin $I^{2}=67.6 \%, p=0.001$; CK $I^{2}=93.2 \%, p<$ 0.001) that were of statistical importance between ALS patients and controls also showed evident heterogeneity between studies as described above, they were further subjected to a meta-regression and subgroup analysis.

Meta-regression analysis suggested that sex (male\%) and the mean age of ALS patients did not have a moderate effect on the significant association between serum ferritin levels and ALS patients. Nevertheless, metaregression of sample size showed a significant association between sample size and WMD for studies analyzing serum ferritin $\left(I^{2}{ }_{-}\right.$res $=39.79 \%$, regression coefficient 


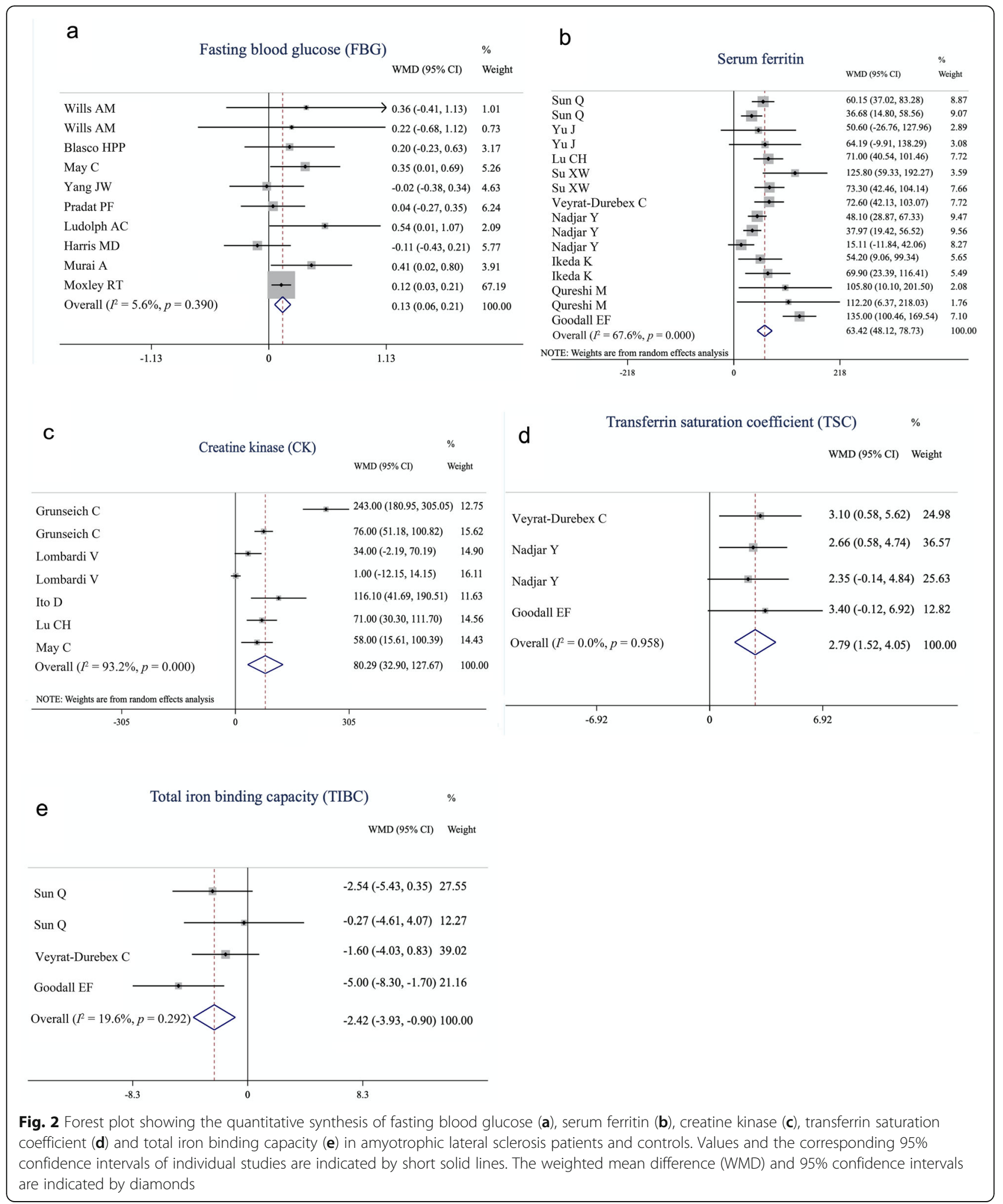

$[\mathrm{SE}]=-0.10[0.04], 95 \% \mathrm{CI}[-0.18,-0.01], p=0.03)$. Meanwhile, sex (male\%), mean age of ALS patients, and disease duration did not affect the outcome of CK metaanalysis. Similarly, meta-regression of the sample size also showed a significant association between sample size and WMD for studies analyzing CK $\left(I^{2}\right.$ res $=$ $80.53 \%$, regression coefficient $[\mathrm{SE}]=0.17[0.05], 95 \% \mathrm{CI}$ $[0.05-0.28], p=0.02)$. 


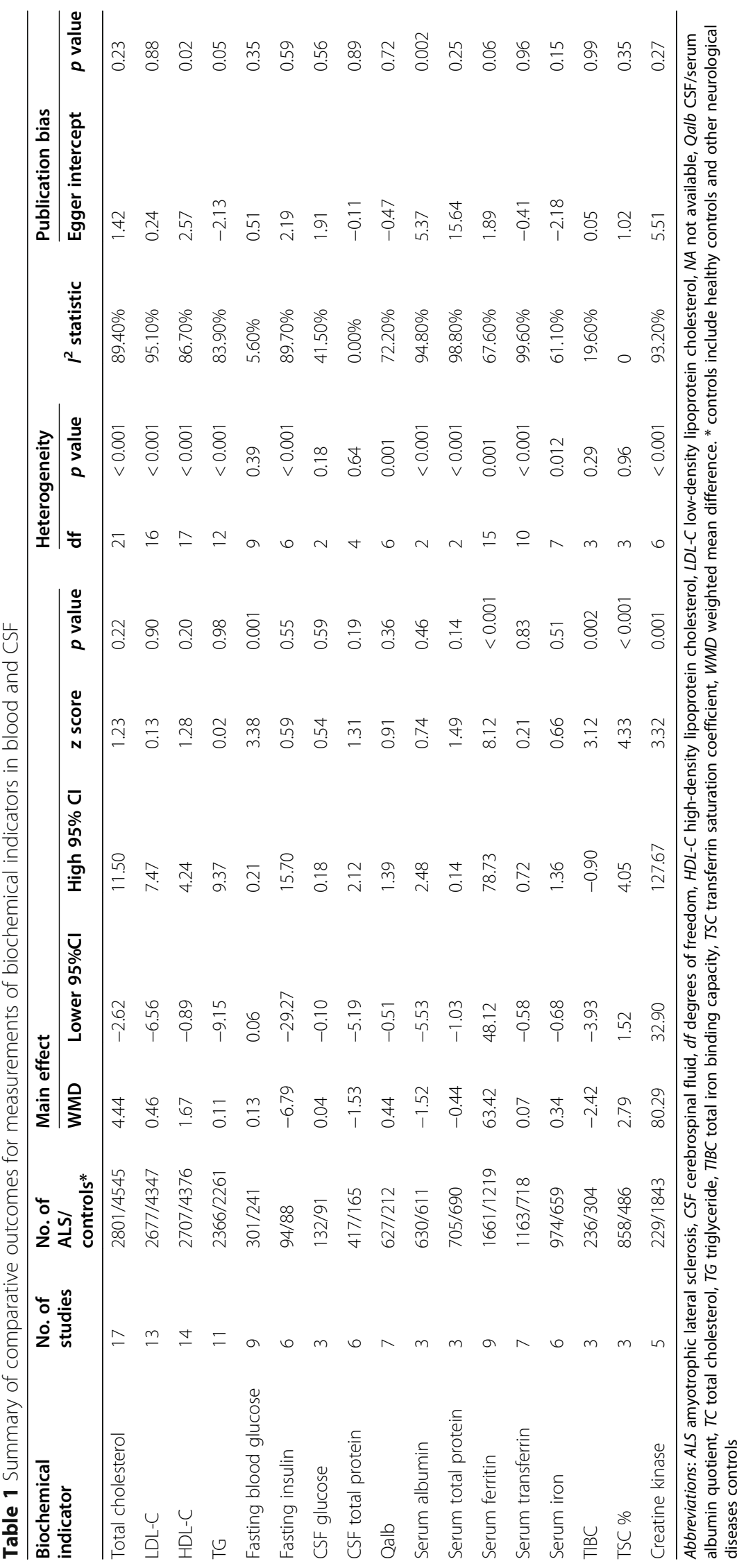


Table 2 Separate analyses based on control group for comparing biochemical indicator levels in blood and CSF

\begin{tabular}{|c|c|c|c|c|c|c|c|c|c|c|c|c|}
\hline \multirow{2}{*}{$\begin{array}{l}\text { Biochemical } \\
\text { indicator }\end{array}$} & \multicolumn{6}{|l|}{ vs $\mathrm{HC}$} & \multicolumn{6}{|c|}{ vs ONDs ${ }^{a}$} \\
\hline & $\begin{array}{l}\text { No. of } \\
\text { studies }\end{array}$ & $\begin{array}{l}\text { No. of ALS/ } \\
\text { controls }\end{array}$ & WMD & $\begin{array}{l}\text { Lower } \\
95 \% \mathrm{Cl}\end{array}$ & $\begin{array}{l}\text { High } \\
95 \% \mathrm{Cl}\end{array}$ & $\begin{array}{l}p \\
\text { value }\end{array}$ & $\begin{array}{l}\text { No. of } \\
\text { studies }\end{array}$ & $\begin{array}{l}\text { No. of ALS/ } \\
\text { controls }\end{array}$ & WMD & $\begin{array}{l}\text { Lower } \\
95 \% \mathrm{Cl}\end{array}$ & $\begin{array}{l}\text { High } \\
95 \% \mathrm{Cl}\end{array}$ & $\begin{array}{l}p \\
\text { value }\end{array}$ \\
\hline $\begin{array}{l}\text { Total } \\
\text { cholesterol }\end{array}$ & 16 & $2762 / 4479$ & 3.98 & -3.48 & 11.44 & 0.30 & 1 & $39 / 66$ & 10.87 & -1.22 & 22.96 & 0.08 \\
\hline LDL-C & 13 & $2677 / 4347$ & 0.46 & -6.56 & 7.47 & 0.90 & 0 & NA & NA & NA & NA & NA \\
\hline HDL-C & 14 & $2707 / 4376$ & 1.67 & -0.89 & 4.24 & 0.20 & 0 & NA & NA & NA & NA & NA \\
\hline TG & 11 & $2366 / 2261$ & 0.11 & -9.15 & 9.37 & 0.98 & 0 & NA & NA & NA & NA & NA \\
\hline $\begin{array}{l}\text { Fasting blood } \\
\text { glucose }\end{array}$ & 8 & $220 / 204$ & 0.13 & 0.05 & 0.21 & 0.001 & 1 & $81 / 37$ & 0.20 & -0.23 & 0.63 & 0.37 \\
\hline Fasting insulin & 6 & $94 / 88$ & -6.79 & -29.27 & 15.70 & 0.55 & 0 & NA & NA & NA & NA & NA \\
\hline CSF glucose & 1 & $20 / 20$ & -0.05 & -0.37 & 0.27 & 0.76 & 2 & $112 / 71$ & 0.06 & -0.10 & 0.21 & 0.45 \\
\hline $\begin{array}{l}\text { CSF total } \\
\text { protein }^{\mathrm{b}}\end{array}$ & 0 & NA & NA & NA & NA & NA & 5 & $312 / 153$ & -1.45 & -5.13 & 2.24 & 0.44 \\
\hline Qalb & 1 & $14 / 20$ & 2.00 & -2.94 & 6.94 & 0.43 & 5 & $508 / 180$ & 0.46 & -0.55 & 1.47 & 0.37 \\
\hline Serum albumin & 3 & 630/611 & -1.52 & -5.53 & 2.48 & 0.46 & 0 & NA & NA & NA & NA & NA \\
\hline $\begin{array}{l}\text { Serum total } \\
\text { protein }\end{array}$ & 3 & $705 / 690$ & -0.44 & -1.03 & 0.14 & 0.14 & 0 & NA & NA & NA & NA & NA \\
\hline Serum ferritin & 9 & $1638 / 1217$ & 63.43 & 48.12 & 78.73 & $\begin{array}{l}< \\
0.001\end{array}$ & 2 & $572 / 255$ & 58.72 & 29.23 & 88.21 & $\begin{array}{l}< \\
0.001\end{array}$ \\
\hline $\begin{array}{l}\text { Serum } \\
\text { transferrin }^{c}\end{array}$ & 6 & $974 / 659$ & -0.13 & -0.17 & -0.08 & $\begin{array}{l}< \\
0.001^{\mathrm{a}}\end{array}$ & 2 & $184 / 83$ & 0.81 & -1.34 & 2.96 & 0.46 \\
\hline Serum iron & 6 & $974 / 659$ & 0.34 & -0.68 & 1.37 & 0.51 & 1 & $72 / 38$ & -0.49 & -2.70 & 1.71 & 0.66 \\
\hline TIBC & 3 & $236 / 304$ & -2.42 & -3.93 & -0.90 & 0.002 & 1 & $72 / 38$ & -1.74 & -5.39 & 1.91 & 0.35 \\
\hline TSC \% & 3 & $858 / 486$ & 2.79 & 1.52 & 4.05 & $\begin{array}{l}< \\
0.001\end{array}$ & 0 & NA & NA & NA & NA & NA \\
\hline Creatine kinase & 5 & 229/1843 & 80.29 & 32.90 & 127.67 & 0.001 & 0 & NA & NA & NA & NA & NA \\
\hline
\end{tabular}

Abbreviations: $A L S$ amyotrophic lateral sclerosis, Cl confidence interval, CSF cerebrospinal fluid, $H C$ healthy control, $H D L-C$ high-density lipoprotein cholesterol, $L D L-$ C low-density lipoprotein cholesterol, NA not available, OND other neurological disease, Qalb CSF/serum albumin quotient, TG triglyceride, TIBC total iron-binding capacity, TSC\% transferrin saturation coefficient, WMD weighted mean difference

a: ONDs are other neurological diseases excluding ALS-related disease. Note: only one study compared ALS with lower motor neuron disease on total protein in CSF [Süssmuth. S. 2010]

b: Süssmuth. $S$ et al. compared total protein in CSF and Qalb between ALS patients and lower motor neuron disease but the results did not have statistical significance (CSF total protein: WMD $=-6.90,95 \% \mathrm{Cl}[-36.23-22.43], p=0.65$; Qalb: WMD $=2.00,95 \% \mathrm{Cl}[-2.94-6.94], p=0.47$ )

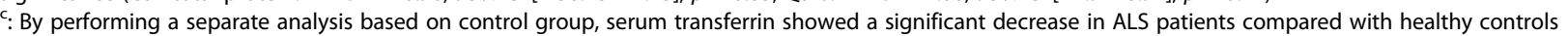
other than ONDs

For serum ferritin, subgroup analysis based on $\operatorname{sex}(n=$ 6 studies) revealed no heterogeneity among studies either in males $\left(\mathrm{Q}=5.57, I^{2}=10.3 \%, p=0.35\right)$ or in females $(\mathrm{Q}$ $=6.38, I^{2}=21.6 \%, p=0.271$ ) (Fig. $4 \mathrm{a}$ ), and ferritin was significantly elevated in both male (WMD $=59.60,95 \% \mathrm{CI}$ [44.36-74.83], $p<0.001)$ and female (WMD $=48.39,95 \%$ CI [37.21-59.58], $p<0.001)$ ALS patients compared with that in sex-matched controls. In addition, after stratifying studies into the large sample group (sample size greater than average) and the small sample group (sample size less than the average), the heterogeneity was reduced to $I^{2}<$ $50 \%$ (large sample group: $\mathrm{Q}=13.25, I^{2}=47.2 \%, p=0.07$; small sample group: $\mathrm{Q}=11.37, I^{2}=47.2 \%, p=0.08$ ). Both the large $(n=8, \mathrm{WMD}=53.85,95 \% \mathrm{CI}$ [45.07-62.64], $p$ $<0.001)$ and small sample groups $(n=7, \mathrm{WMD}=59.59$, 95\% CI [51.51-67.68], $p<0.001)$ showed increased levels of serum ferritin in ALS patients. Compared with controls, there were significantly higher CK levels in male $(n=3$, $\mathrm{WMD}=101.36,95 \% \mathrm{CI}$ [7.79-194.93], $p=0.03$ ) and female $(n=2$, WMD $=66.97,95 \%$ CI [40.51-93.42], $p<$ $0.001)$ ALS patients. However, the between-study heterogeneity was increased in the male group $\left(\mathrm{Q}=63.38, I^{2}=\right.$ $95.3 \%, p<0.001)$, and decreased in the female group $(n=$ $\left.2, \mathrm{Q}=1.32, I^{2}=24.3 \%, p=0.251\right)$ (Fig. $4 \mathrm{~b}$ ).

\section{Potential publication bias assessment and sensitivity analysis}

Sensitivity analysis demonstrated that the pooled WMDs of FBG, ferritin, TIBS, TBC\%, and CK were stable, which indicated that the results were not affected by any single study. Furthermore, Egger's test showed that there was no risk of publication bias among studies analyzing FBG, ferritin, TIBS, $\mathrm{TBC} \%$, and CK indicators in ALS (Table 1). 

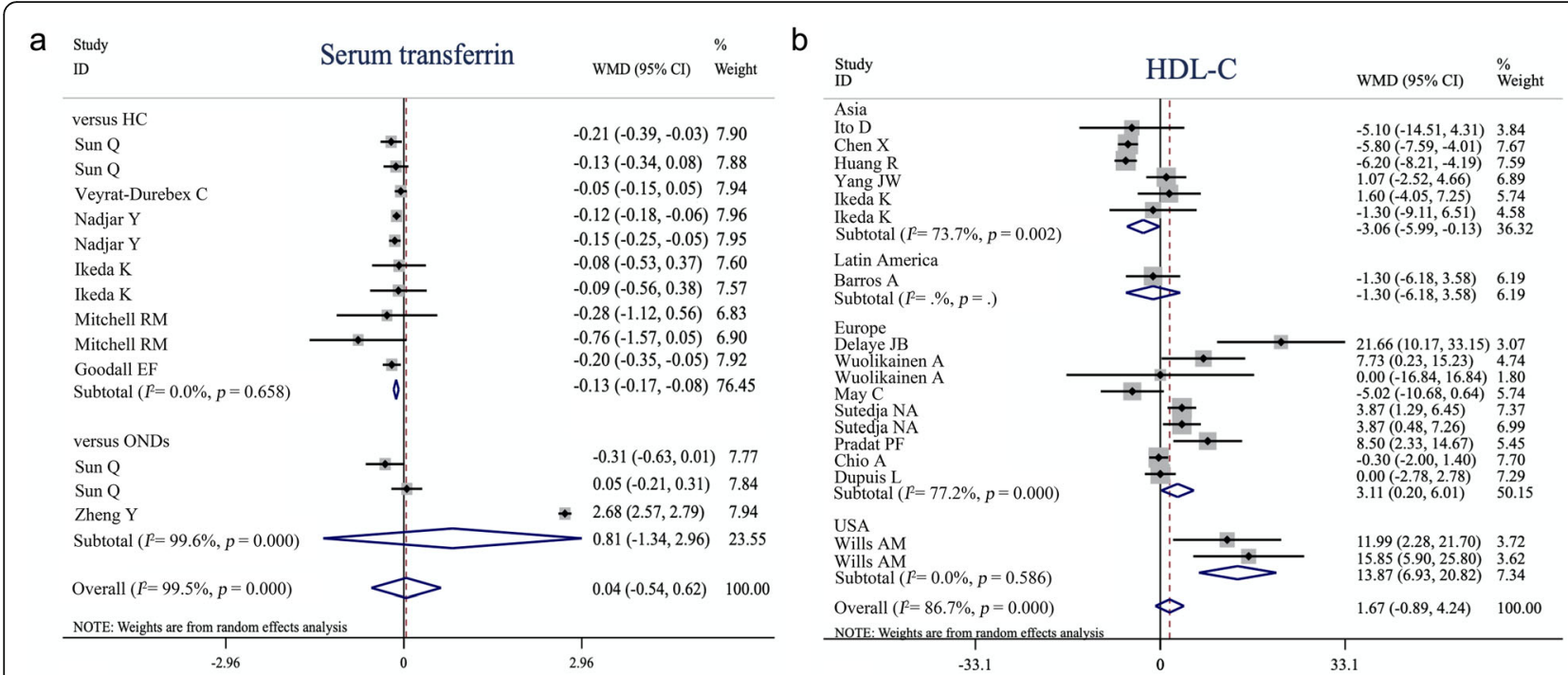

Fig. 3 Forest plot showing separate analysis of serum transferrin based on control type (a) and high-density lipoprotein cholesterol based on ethnicity (b). Values and the corresponding 95\% confidence intervals of individual studies are indicated by short solid lines. The weighted mean difference (WMD) and 95\% confidence intervals are indicated by diamonds

\section{Association analysis}

Among the studies included in the meta-analysis, five studies underwent a survival analysis of serum ferritin levels and four studies underwent a survival analysis of CK levels in ALS patients. Given that their conclusions were not consistent, we then conducted a meta-analysis of the association of high vs. low levels of ferritin and CK with the overall survival of ALS patients. The associations between serum ferritin or CK levels and survival are shown in the forest plot (Fig. 5). The random-effects model was used because there was substantial heterogeneity among the studies related to ferritin $(\mathrm{Q}[\mathrm{df}=5]=$ $\left.16.56, I^{2}=69.8 \%, p=0.005\right)$. The pooled HR suggested significantly reduced survival $(\mathrm{HR}=1.38,95 \%$ CI $[1.02-$ 1.88], $p=0.04$ ) of ALS patients with elevated serum ferritin levels, whereas CK levels did not affect the survival of patients with ALS (HR $=1.00,95 \%$ CI [0.67-1.49], $p=$ $0.99)$. No publication bias was identified in the Egger test (serum ferritin: Egger intercept $=1.35, p>0.34$; CK: Egger intercept $=-0.036, p>0.87)$. The characteristics
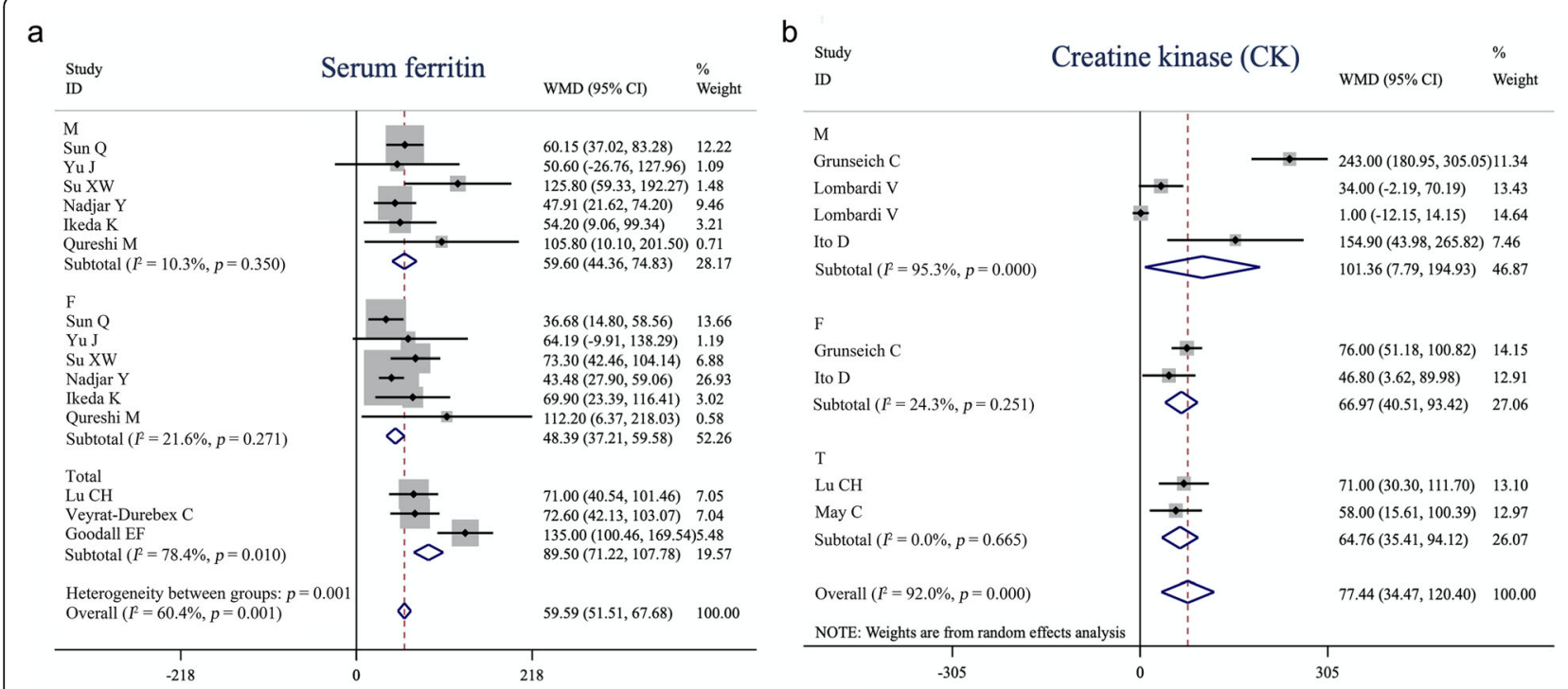

Fig. 4 Forest plot showing subgroup analysis of serum ferritin (a) and creatine kinase (b) based on sex. M: male group, F: female group, Total: combined male and female patients. Values and the corresponding $95 \%$ confidence intervals of individual studies are indicated by short solid lines. The weighted mean difference (WMD) and 95\% confidence intervals are indicated by diamonds 


Study
$\mathrm{ID}$

and summary statistics of studies included in the metaanalysis of survival are provided in Tables S2-S3.

The number of studies which showed precise biochemical values and survival analysis on FBG $(n=1)$, TSC $(n=0)$, and TIBC $(n=0)$ was not sufficient for meta-analysis; therefore, we did not perform metaanalysis on the associations of the three indicators with patient survival.

\section{Discussion}

In this meta-analysis study, we compared 17 biochemical indicators between 5454 ALS patients and 7986 control subjects from 46 original studies, and found evidence of significantly higher FBG, ferritin, TSC and CK, and significantly lower TIBC in ALS patients than in controls. Only FBG presented a small ES $(0<\mathrm{ES}<1)$, while the other four indicators showed results associated with a large ES $(E S>1)$. In addition, within the five ALS-linked indicators, we found that the elevated serum ferritin levels were associated with reduced survival in patients with ALS. Sensitivity analysis indicated that the findings on FBG, ferritin, TIBC, TSC and CK in the ALS patients would not be affected by any single study included, suggesting the robustness of these results.

The difference in these clinical biochemical indicators between ALS patients and controls suggests that ALS is a multi-systemic disease with motor neuron degeneration, rather than a restricted central nervous system disorder [68]. Among the five ALS-associated indicators identified in the meta-analysis, three are related to iron metabolism. In addition, the serum transferrin level was significantly lower in ALS patients than in healthy controls, suggesting that the disruption of iron homeostasis is involved in the pathophysiological process of ALS [69]. Ferritin as a marker of body iron storage plays a role in iron sequestration where it functions as a ferroxidase, converting $\mathrm{Fe}^{2+}$ to $\mathrm{Fe}^{3+}$ as iron is internalized and sequestered in the ferritin mineral core [70, 71]. As ferritin can prevent iron from generating reactive oxygen species, it is considered to have an anti-oxidative cellular function [72, 73]. Under chronic inflammatory conditions, the ferritin levels are increased and TIBC, which is a measure of total serum transferrin (apotransferrin, monotransferrin, and diferric transferrin), could be decreased [74]. Therefore, the disruption of iron homeostasis might be the result of immune system activation [75], which is considered as one of the pathogeneses of ALS. TSC is often elevated in patients with HFE-linked hemochromatosis, while the H63D HFE gene polymorphism is considered as a risk factor for ALS [55, 76, 77]. Moreover, some imaging studies [78, 79] have suggested that ALS patients may be affected by iron overload. Our meta-analysis showed a negative association between serum ferritin levels and survival in ALS patients. Previous studies [80-82] have shown that the conservative iron chelation therapy may potentially serve as a treatment option to reduce iron accumulation and improve prognosis in ALS patients. Furthermore, our meta-analysis of survival data suggested the predictive role of serum ferritin in disease prognosis; thus, the ferritin level could be used as a tool to stratify patients in clinical trials. However, it remains to clarify whether the 
disruption of iron homeostasis is a cause or a consequence of ALS development, why ALS patients have increased iron body storage and how it relates to decreased survival. Further studies are needed to address these questions. The difference between the current meta-analysis and the previous one [83] was that we conducted a more comprehensive literature search that included more studies, with some inconsistent results, and that we analyzed the association between ALS patients and survival time and found a negative correlation between ferritin level and the overall survival.

Regarding the elevation of CK levels in ALS patients, Ito found that the serum CK was elevated not only in the early stages of ALS but also before its onset, achieved a maximum level around onset, and then declined after onset [18]. The pathophysiological mechanisms underlying this phenomenon might be the muscle cramp or active muscle denervation leading to the elevation of serum CK [84]. In addition, a study has reported denervation-induced membrane instability in muscle tissue and leakage of CK into the blood [85]. Hence, it is reasonable to suggest that the elevation of serum CK in ALS is caused by membrane instability or the destruction of muscle tissue due to the denervation and hyperexcitability of motor neurons [18]. Regarding the increase in FBG, there might be impaired control of fasting glucose levels and dysfunction of the glucose-insulin axis in patients with ALS. Considering the absence of beta cell dysfunction, fasting insulin levels and HbA1c did not significantly differ between ALS patients and controls, suggesting no evidence of insulin resistance [86], which is not consistent with our previous original study [6]. The potential mechanism underlying the elevation of FBG may be the chronic oxidative stress resulting from higher energy expenditure than intake in patients with ALS [68]. That is to say, some ALS patients with bulbar paralysis leading to dysphagia and an increase in resting energy expenditure [87-89] develop hypometabolism due to the denervation-linked muscle wasting. Long-term hypometabolism can activate chronic oxidative stress [90]. Therefore, the elevation of FBG levels is related to the oxidative stress, which also participates in the development of ALS. However, as described in our previous study [6], the FBG test is an excellent test for the "in the moment" glucose level, which, however, provides limited information on the trend of glucose level change over time. This is a limitation of our meta-analysis as there was not enough data on HbA1c or postprandial blood glucose hours after eating a meal, preventing us from evaluating changes in glucose level over time in ALS patients compared with that in controls. Regarding the interesting finding of ethnographic heterogeneity of HDL-C difference between ALS patients and controls, we suppose that the patient ethnicity may have an effect on the ALS phenotype. To our knowledge, this is the first report of the phenomenon of HDL-C. More research is needed to confirm this result.

Heterogeneity analysis using the $I^{2}$ statistic and Cochrane Q test showed that the between-study heterogeneity of the 17 biochemical indicators varied from zero to high. Among the five indicators identified as associated with ALS, only serum ferritin and CK showed medium to high heterogeneity among studies. Therefore, we performed meta-regression analysis and subgroup analysis of these two indicators to explore confounders of the between-study heterogeneity. Meta-regression analysis suggested that the outcomes of both serum ferritin and CK might be influenced by the sample size, but not by other potential factors including sex (male\%) and mean age of ALS patients. Due to the lack of complete data on disease duration in studies involving serum ferritin, we only conducted the meta-regression analysis on disease duration for $\mathrm{CK}$, and found no influence of disease duration on the result. Therefore, the sample size of each study investigating serum ferritin and CK is one of the sources of heterogeneity, as partially confirmed by subgroup analysis of serum ferritin stratified by sample size. Subgroup analysis of serum ferritin stratified by sex not only reduced the heterogeneity between studies but also consistently revealed a significant association of ferritin with ALS, suggesting that sex was the second confounder of heterogeneity. Interestingly, Sun et al. [31] also found different distribution of serum ferritin in male and female patients with multiple system atrophy. For CK, despite the evident association in subgroup analysis based on sex, the between-study heterogeneity in male patients remained high, while the heterogeneity in female patients decreased significantly, suggesting that sex might be a confounder of between-study heterogeneity for CK.

There were some limitations in this study. First, some studies included in this analysis did not provide information on disease duration or disease status, which prevented us from performing a subgroup analysis of whether the differences in these indicators were associated with disease duration or severity. Second, we did not find indicators linked with energy metabolism in the CSF between patients with ALS and control subjects. Due to the hypothesis that CSF is a window to the brain, more biochemical indicators in the CSF should be investigated in further studies. Third, we did not perform meta-analysis on the associations of FBG, TSC and TIBC with survival due to the limited number of studies. Last, none of the biomarkers discussed in this meta-analysis are specific to ALS, and thus do not have potential use as diagnostic markers. Therefore, the indicators identified in our study should be confirmed in the future. 
In conclusion, the findings of our meta-analysis revealed elevated FBG, ferritin, TSC, and CK levels and decreased TIBC in patients with ALS. In addition, the serum ferritin level was negatively associated with the overall survival of patients with ALS. These results provide further evidence that abnormalities in energy metabolism, disruption of iron homeostasis caused by oxidative stress, and abnormal immune activation participate in the pathophysiological process of ALS. Further studies are required to address whether these abnormalities are causes or consequences of ALS development and how they influence ALS. More studies are needed to translate the treatment potential of conservative iron chelation to benefit ALS patients.

\section{Supplementary Information}

The online version contains supplementary material available at https://doi. org/10.1186/s40035-020-00228-9.

Additional file 1: Table S1. Characteristics of included studies measuring biochemical indicator levels in blood and CSF. Table S2. Characteristics and summary statistics of studies showing the association of serum ferritin with survival in ALS patients. Table S3. Characteristics and summary statistics of studies showing the association of creatine kinase with survival in ALS patients.

Additional file 2: Fig. S1. Forest plot showing separate analysis of total cholesterol, low-density lipoprotein cholesterol, triglyceride, fasting blood glucose, fasting insulin, CSF glucose, CSF total protein, Qalb, serum albumin, serum total protein, serum ferritin, serum transferrin, serum iron, total iron binding capacity, transferrin saturation coefficient and creatine kinase based on ethnicity, respectively. Values and the corresponding $95 \%$ confidence intervals of individual studies are indicated by short solid lines. The weighted mean difference (WMD) and 95\% confidence intervals are indicated by diamonds.

\section{Abbreviations}

ALS: Amyotrophic lateral sclerosis; Cl: Confidence interval; CK: Creatine kinase; CSF: Cerebrospinal fluid; ES: Effective size; HDL: High-density lipoprotein; HR: Hazard ratios; LDL: Low-density lipoprotein; NDDs: Neurodegenerative diseases; Qalb: CSF/serum albumin quotient; SD: Standard deviation; TC: Total cholesterol; TG: Triglyceride; TIBC: Total iron-binding capacity; TSC: Transferrin saturation coefficient; WMD: Weighted mean difference

\section{Acknowledgements}

We would like to thank all authors of the original research studies included in this meta-analysis. We thank Dr. Yang Zhang from Department of Neurosurgery, West China Hospital for help with software issues and English writing.

\section{Authors' contributions}

YPC and HS designed the whole study and gave suggestions on revising the article. YFC searched and selected the studies, analyzed the data, drafted and revised the article. YPC prepared figures. All authors read and approved the final manuscript.

\section{Funding}

This meta-analysis was supported by the National Key Research and Development Program of China (2016YFC0901504).

\section{Availability of data and materials}

All data generated or analyzed during this study are included in this article and its supplementary materials.

Ethics approval and consent to participate Not applicable.
Consent for publication

Not applicable.

\section{Competing interests}

The authors declare that they have no competing interests.

Received: 9 October 2020 Accepted: 23 December 2020

Published online: 08 January 2021

\section{References}

1. Kiernan MC, Vucic S, Cheah BC, Turner MR, Eisen A, Hardiman O, et al. Amyotrophic lateral sclerosis. Lancet. 2011;377(9769):942-55.

2. Brown $\mathrm{RH}, \mathrm{Al}$-Chalabi A. Amyotrophic lateral sclerosis. N Engl J Med. 2017; 377(2):162-72

3. Rothstein JD. Current hypotheses for the underlying biology of amyotrophic lateral sclerosis. Ann Neurol. 2009;65(Suppl 1):S3-9.

4. Chiò A, Logroscino G, Traynor BJ, Collins J, Simeone JC, Goldstein LA, et al. Global epidemiology of amyotrophic lateral sclerosis: a systematic review of the published literature. Neuroepidemiology. 2013;41(2):118-30.

5. Andersen PM, Abrahams S, Borasio GD, de Carvalho M, Chio A, Van Damme $P$, et al. EFNS guidelines on the clinical management of amyotrophic lateral sclerosis (MALS)--revised report of an EFNS task force. Eur J Neurol. 2012; 19(3):360-75.

6. Qian-Qian W, Yongping C, Bei C, Ru Wei O, Lingyu Z, Yanbing H, et al. Blood hemoglobin A1c levels and amyotrophic lateral sclerosis survival. Mol Neurodegener. 2017:12:1-7.

7. Mariosa D, Hammar N, Malmström H, Ingre C, Jungner I, Ye W, et al. Blood biomarkers of carbohydrate, lipid, and apolipoprotein metabolisms and risk of amyotrophic lateral sclerosis: a more than 20-year follow-up of the Swedish AMORIS cohort. Ann Neurol. 2017:81(5):718-28.

8. Pradat PF, Bruneteau G, Gordon PH, Dupuis L, Bonnefont-Rousselot D, Simon $D$, et al. Impaired glucose tolerance in patients with amyotrophic lateral sclerosis. Amyotroph Lateral Scler. 2010;11(1-2):166-71.

9. González De Aguilar JL. Lipid biomarkers for amyotrophic lateral sclerosis. Front Neurol. 2019;10:284.

10. Chen X, Yazdani S, Piehl F, Magnusson PKE, Fang F. Polygenic link between blood lipids and amyotrophic lateral sclerosis. Neurobiol Aging. 2018;67:202 e1-.e6.

11. Abdel-Khalik J, Yutuc E, Crick PJ, Gustafsson J, Warner M, Roman G, et al. Defective cholesterol metabolism in amyotrophic lateral sclerosis. J Lipid Res. 2017;58(1):267-78.

12. Chio A, Calvo A, Bovio G, Canosa A, Bertuzzo D, Galmozzi F, et al. Amyotrophic lateral sclerosis outcome measures and the role of albumin and creatinine: a population-based study. JAMA Neurol. 2014;71(9):1134-42.

13. Chen X, Wei QQ, Chen Y, Cao B, Ou R, Hou Y, et al. Clinical disease stage related changes of serological factors in amyotrophic lateral sclerosis. Amyotroph Lateral Scler Frontotemporal Degener. 2019;20(1-2):53-60.

14. Mandrioli J, Rosi E, Fini N, Fasano A, Raggi S, Fantuzzi A, et al. Changes in routine laboratory tests and survival in amyotrophic lateral sclerosis. Neurol Sci. 2017;38(12):2177-82.

15. Masaldan S, Bush Al, Devos D, Rolland AS, Moreau C. Striking while the iron is hot: Iron metabolism and ferroptosis in neurodegeneration. Free Radic Biol Med. 2019;133:221-33.

16. Zheng Y, Gao L, Wang D, Zang D. Elevated levels of ferritin in the cerebrospinal fluid of amyotrophic lateral sclerosis patients. Acta Neurol Scand. 2017;136(2):145-50.

17. Lu CH, Allen K, Oei F, Leoni E, Kuhle J, Tree T, et al. Systemic inflammatory response and neuromuscular involvement in amyotrophic lateral sclerosis. Neurol Neuroimmunol Neuroinflamm. 2016:3(4):e244.

18. Ito D, Hashizume A, Hijikata Y, Yamada S, Iguchi Y, lida M, et al. Elevated serum creatine kinase in the early stage of sporadic amyotrophic lateral sclerosis. J Neurol. 2019;266(12):2952-61.

19. Andrés-Benito P, Moreno J, Domínguez R, Aso E, Povedano M, Ferrer I. Inflammatory gene expression in whole peripheral blood at early stages of sporadic amyotrophic lateral sclerosis. Front Neurol. 2017;8:546.

20. Wendt S, Dedeoglu A, Speer O, Wallimann T, Beal MF, Andreassen OA. Reduced creatine kinase activity in transgenic amyotrophic lateral sclerosis mice. Free Radic Biol Med. 2002;32(9):920-6.

21. Moher D, Liberati A, Tetzlaff J, Altman DG. Preferred reporting items for systematic reviews and meta-analyses: the PRISMA statement. PLoS Med. 2009;6(7):e1000097. 
22. Wan X, Wang W, Liu J, Tong T. Estimating the sample mean and standard deviation from the sample size, median, range and/or interquartile range. BMC Med Res Methodol. 2014;14:135.

23. Higgins JP, Thomas J, Chandler J, Cumpston M, Li T, Page MJ, et al. Cochrane Handbook for Systematic Reviews of Interventions. Hoboken: Wiley; 2019. https://onlinelibrary.wiley.com/doi/abs/10.1002/9781119536604.ch12.

24. Tierney JF, Stewart LA, Ghersi D, Burdett S, Sydes MR. Practical methods for incorporating summary time-to-event data into meta-analysis. Trials. 2007;8:16.

25. Mittlböck M, Heinzl H. A simulation study comparing properties of heterogeneity measures in meta-analyses. Stat Med. 2006;25(24):4321-33.

26. Irwig L, Macaskill P, Berry G, Glasziou P. Bias in meta-analysis detected by a simple, graphical test. Graphical test is itself biased. BMJ. 1998;316(7129):470 author reply 470-1

27. Wu Y, Yang $X$, Li X, Wang H, Wang T. Elevated cerebrospinal fluid homocysteine is associated with blood-brain barrier disruption in amyotrophic lateral sclerosis patients. Neurol Sci. 2020;41(7):1865-72.

28. Grunseich C, Patankar A, Amaya J, Watts JA, Li D, Ramirez P, et al. Clinical and molecular aspects of senataxin mutations in amyotrophic lateral sclerosis 4. Ann Neurol. 2020;87(4):547-55.

29. Costa J, Streich L, Pinto S, Pronto-Laborinho A, Nimtz M, Conradt HS, et al. Exploring cerebrospinal fluid igg n-glycosylation as potential biomarker for amyotrophic lateral sclerosis. Mol Neurobiol. 2019:56(8):5729-39.

30. Ikenaka KMDP, Atsuta NMDP, Maeda YP, Hotta YP, Nakamura RMDP, Kawai $K P$, et al. Increase of arginine dimethylation correlates with the progression and prognosis of ALS. Neurology. 2019;92(16):e1868-e77.

31. Sun $Q$, Yang F, Wang H, Cui F, Li Y, Li S, et al. Elevated serum ferritin level as a predictor of reduced survival in patients with sporadic amyotrophic lateral sclerosis in China: a retrospective study. Amyotroph Lateral Scler Frontotemporal Degener. 2019;20(3-4):186-91.

32. Lombardi V, Querin G, Ziff OJ, Zampedri L, Martinelli I, Heller C, et al. Muscle and not neuronal biomarkers correlate with severity in spinal and bulbar muscular atrophy. Neurology. 2019;92(11):e1205-e11.

33. Barros A, Dourado MET Jr, Pedrosa LFC, Leite-Lais L. Association of copper status with lipid profile and functional status in patients with amyotrophic lateral sclerosis. J Nutr Metab. 2018;2018:5678698.

34. Rossi D, Volanti P, Brambilla L, Colletti T, Spataro R, La Bella V. CSF neurofilament proteins as diagnostic and prognostic biomarkers for amyotrophic lateral sclerosis. J Neurol. 2018;265(3):510-21.

35. Kułakowska A, Tarasiuk J, Kapica-Topczewska K, Chorąży M, Pogorzelski R, Kulczyńska-Przybik A, et al. Pathophysiological implications of actin-free Gcglobulin concentration changes in blood plasma and cerebrospinal fluid collected from patients with Alzheimer's disease and other neurological disorders. Adv Clin Exp Med. 2018;27(8):1075-80.

36. Yu J, Wang N, Qi F, Wang X, Zhu Q, Lu Y, et al. Serum ferritin is a candidate biomarker of disease aggravation in amyotrophic lateral sclerosis. Biomed Rep. 2018:9(4):333-8.

37. Kim SM, Noh MY, Kim H, Cheon SY, Lee KM, Lee J, et al. 25Hydroxycholesterol is involved in the pathogenesis of amyotrophic lateral sclerosis. Oncotarget. 2017;8(7):11855-67.

38. Delaye JB, Patin F, Piver E, Bruno C, Vasse M, Vourc'h P, et al. Low IDL-B and high LDL-1 subfraction levels in serum of ALS patients. J Neurol Sci. 2017; 380:124-7.

39. Nagase $M$, Yamamoto $Y$, Miyazaki $Y$, Yoshino $H$. Increased oxidative stress in patients with amyotrophic lateral sclerosis and the effect of edaravone administration. Redox Rep. 2016;21(3):104-12.

40. Feneberg $E$, Steinacker $P$, Volk AE, Weishaupt JH, Wollmer MA, Boxer A, et al. Progranulin as a candidate biomarker for therapeutic trial in patients with ALS and FTLD. J Neural Transm (Vienna). 2016:123(3):289-96.

41. Henriques A, Blasco H, Fleury MC, Corcia P, Echaniz-Laguna A, Robelin L, et al. Blood cell palmitoleate-palmitate ratio is an independent prognostic factor for amyotrophic lateral sclerosis. PLoS One. 2015;10(7):e0131512.

42. Su XW, Clardy SL, Stephens HE, Simmons Z, Connor JR. Serum ferritin is elevated in amyotrophic lateral sclerosis patients. Amyotroph Lateral Scler Frontotemporal Degener. 2015;16(1/2):102-7.

43. May C, Nordhoff E, Casjens S, Turewicz M, Eisenacher M, Gold R, et al. Highly immunoreactive lgG antibodies directed against a set of twenty human proteins in the sera of patients with amyotrophic lateral sclerosis identified by protein array. PLoS One. 2014;9(2):e89596.

44. Wuolikainen A, Acimovic J, Lövgren-Sandblom A, Parini P, Andersen PM, Björkhem I. Cholesterol, oxysterol, triglyceride, and coenzyme Q homeostasis in ALS. Evidence against the hypothesis that elevated 27hydroxycholesterol is a pathogenic factor. PLoS One. 2014;9(11):e113619.

45. Wills AM, Hubbard J, Macklin EA, Glass J, Tandan R, Simpson EP, et al. Hypercaloric enteral nutrition in patients with amyotrophic lateral sclerosis: a randomised, double-blind, placebo-controlled phase 2 trial. Lancet. 2014; 383(9934):2065-72.

46. Huang R, Guo X, Chen X, Zheng Z, Wei Q, Cao B, et al. The serum lipid profiles of amyotrophic lateral sclerosis patients: a study from south-West China and a meta-analysis. Amyotroph Lateral Scler Frontotemporal Degener. 2015;16(5-6):359-65.

47. Blasco HPP, Nadal-Desbarats LP, Pradat P-FMDP, Gordon PHMDP, Antar C, VeyratDurebex CP, et al. Untargeted 1H-NMR metabolomics in CSF: toward a diagnostic biomarker for motor neuron disease. Neurology. 2014;82(13):1167-74.

48. Veyrat-Durebex C, Corcia P, Mucha A, Benzimra S, Mallet C, Gendrot C, et al. Iron metabolism disturbance in a French cohort of ALS patients. Biomed Res Int. 2014;2014:485723.

49. Yang JW, Kim SM, Kim HJ, Kim JE, Park KS, Kim SH, et al. Hypolipidemia in patients with amyotrophic lateral sclerosis: a possible gender difference? J Clin Neurol. 2013;9(2):125-9.

50. Ticozzi N, Tiloca C, Mencacci NE, Morelli C, Doretti A, Rusconi D, et al. Oligoclonal bands in the cerebrospinal fluid of amyotrophic lateral sclerosis patients with disease-associated mutations. J Neurol. 2013;260(1):85-92.

51. Ikeda K, Hirayama T, Takazawa T, Kawabe K, Iwasaki Y. Relationships between disease progression and serum levels of lipid, urate, creatinine and ferritin in Japanese patients with amyotrophic lateral sclerosis: a crosssectional study. Intern Med. 2012;51(12):1501-8.

52. Nadjar $Y$, Gordon $P$, Corcia $P$, Bensimon $G$, Pieroni L, Meininger $V$, et al. Elevated serum ferritin is associated with reduced survival in amyotrophic lateral sclerosis. PLoS One. 2012;7(9):1-6.

53. Sutedja NA, van der Schouw YT, Fischer K, Sizoo EM, Huisman MH, Veldink $J \mathrm{H}$, et al. Beneficial vascular risk profile is associated with amyotrophic lateral sclerosis. J Neurol Neurosurg Psychiatry. 2011;82(6):638-42.

54. Süssmuth SD, Sperfeld AD, Ludolph AC, Tumani H. Hypercapnia is a possible determinant of the function of the blood-cerebrospinal fluid barrier in amyotrophic lateral sclerosis. Neurochem Res. 2010;35(7):1071-4.

55. Mitchell RM, Simmons Z, Beard JL, Stephens HE, Connor JR. Plasma biomarkers associated with ALS and their relationship to iron homeostasis. Muscle Nerve. 2010;42(1):95-103.

56. Chio A, Calvo A, llardi A, Cavallo E, Moglia C, Mutani R, et al. Lower serum lipid levels are related to respiratory impairment in patients with ALS. Neurology. 2009;73(20):1681-5.

57. Dupuis L, Corcia P, Fergani A, De Aguilar JL, Bonnefont-Rousselot D, Bittar R, et al. Dyslipidemia is a protective factor in amyotrophic lateral sclerosis. Neurology. 2008;70(13):1004-9.

58. Qureshi M, Brown RH Jr, Rogers JT, Cudkowicz ME. Serum ferritin and metal levels as risk factors for amyotrophic lateral sclerosis. Open Neurol J. 2008;2: $51-4$.

59. Goodall EF, Haque MS, Morrison KE. Increased serum ferritin levels in amyotrophic lateral sclerosis (ALS) patients. J Neurology. 2008;255(11):1652-6.

60. Sohmiya M, Tanaka M, Suzuki Y, Tanino Y, Okamoto K, Yamamoto Y. An increase of oxidized coenzyme Q-10 occurs in the plasma of sporadic ALS patients. J Neurol Sci. 2005;228(1):49-53.

61. Yushchenko M, Weber F, Mäder M, Schöll U, Maliszewska M, Tumani H, et al Matrix metalloproteinase-9 (MMP-9) in human cerebrospinal fluid (CSF): elevated levels are primarily related to CSF cell count. J Neuroimmunol. 2000;110(1-2):244-51.

62. Ludolph AC, Langen KJ, Regard M, Herzog H, Kemper B, Kuwert T, et al. Frontal lobe function in amyotrophic lateral sclerosis: a neuropsychologic and positron emission tomography study. Acta Neurol Scand. 1992:85(2):81-9.

63. Harris MD, Davidson MB, Rosenberg CS. Insulin antagonism is not a primary abnormality of amyotrophic lateral sclerois but is related to disease severity. J Clin Endocrinol Metab. 1986;63(1):41-6.

64. Jockers-Wretou E, Vassilopoulos D. Serum creatine kinase B subunit levels in neurogenic atrophies. J Neurol. 1985;232(4):236-9.

65. Reyes ET, Perurena OH, Festoff BW, Jorgensen R, Moore WV. Insulin resistance in amyotrophic lateral sclerosis. J Neurol Sci. 1984;63(3):317-24.

66. Murai A, Miyahara T, Tanaka T, Kaneko T, Sako Y, Kameyama M. Abnormalities of lipoprotein and carbohydrate metabolism in degenerative diseases of the nervous system--motor neuron disease and spinocerebellar degeneration. Tohoku J Exp Med. 1983;139(4):365-76. 
67. Moxley RT, Griggs RC, Forbes GB, Goldblatt D, Donohoe K. Influence of muscle wasting on oral glucose tolerance testing. Clin Sci (Lond). 1983; 64(6):601-9.

68. Dupuis L, Pradat PF, Ludolph AC, Loeffler JP. Energy metabolism in amyotrophic lateral sclerosis. Lancet Neurol. 2011;10(1):75-82.

69. Kim Y, Connor JR. The roles of iron and HFE genotype in neurological diseases. Mol Asp Med. 2020;75:100867.

70. Knovich MA, Storey JA, Coffman LG, Torti SV, Torti FM. Ferritin for the clinician. Blood Rev. 2009;23(3):95-104.

71. Singh AV, Vyas V, Montani E, Cartelli D, Parazzoli D, Oldani A, et al. Investigation of in vitro cytotoxicity of the redox state of ionic iron in neuroblastoma cells. J Neurosci Rural Pract. 2012;3(3):301-10.

72. Arosio P, Levi S. Ferritin, iron homeostasis, and oxidative damage. Free Radic Biol Med. 2002;33(4):457-63.

73. Sheykhansari S, Kozielski K, Bill J, Sitti M, Gemmati D, Zamboni P, et al. Redox metals homeostasis in multiple sclerosis and amyotrophic lateral sclerosis: a review. Cell Death Dis. 2018;9(3):348.

74. Kell DB, Pretorius E. Serum ferritin is an important inflammatory disease marker, as it is mainly a leakage product from damaged cells. Metallomics. 2014;6(4):748-73.

75. Ganz T, Nemeth E. Iron homeostasis in host defence and inflammation. Nat Rev Immunol. 2015;15(8):500-10.

76. Tisato V, Zuliani G, Vigliano M, Longo G, Franchini E, Secchiero P, et al. Gene-gene interactions among coding genes of iron-homeostasis proteins and APOE-alleles in cognitive impairment diseases. PLoS One. 2018;13(3): e0193867.

77. Gemmati D, Zeri G, Orioli E, De Gaetano FE, Salvi F, Bartolomei I, et al. Polymorphisms in the genes coding for iron binding and transporting proteins are associated with disability, severity, and early progression in multiple sclerosis. BMC Med Genet. 2012;13:70.

78. Acosta-Cabronero J, Machts J, Schreiber S, Abdulla S, Kollewe K, Petri S, et al. Quantitative susceptibility MRI to detect brain iron in amyotrophic lateral sclerosis. Radiology. 2018;289(1):195-203.

79. Adachi Y, Sato N, Saito Y, Kimura Y, Nakata Y, Ito K, et al. Usefulness of SWI for the detection of iron in the motor cortex in amyotrophic lateral sclerosis. J Neuroimaging. 2015;25(3):443-51.

80. Golko-Perez S, Amit T, Bar-Am O, Youdim MB, Weinreb O. A novel iron chelator-radical scavenger ameliorates motor dysfunction and improves life span and mitochondrial biogenesis in SOD1(G93A) ALS mice. Neurotox Res. 2017;31(2):230-44.

81. Moreau C, Danel V, Devedjian JC, Grolez G, Timmerman K, Laloux C, et al. Could conservative iron chelation lead to neuroprotection in amyotrophic lateral sclerosis? Antioxid Redox Signal. 2018;29(8):742-8.

82. Devos D, Cabantchik ZI, Moreau C, Danel V, Mahoney-Sanchez L, Bouchaoui $\mathrm{H}$, et al. Conservative iron chelation for neurodegenerative diseases such as Parkinson's disease and amyotrophic lateral sclerosis. J Neural Transm (Vienna). 2020;127(2):189-203.

83. Wang L, Li C, Chen X, Li S, Shang H. Abnormal serum iron-status indicator changes in amyotrophic lateral sclerosis (ALS) patients: a meta-analysis. Front Neurol. 2020;11:380.

84. Tai H, Cui L, Liu M, Guan Y, Li X, Shen D, et al. Creatine kinase level and its relationship with quantitative electromyographic characteristics in amyotrophic lateral sclerosis. Clin Neurophysiol. 2018;129(5):926-30.

85. Linkhart TA, Wilson BW. Appearance of acetylcholinesterase and creatine kinase in plasma of normal chickens after denervation. J Neurol Sci. 1975; 26(2):193-201.

86. Borai A, Livingstone C, Abdelaal F, Bawazeer A, Keti V, Ferns G. The relationship between glycosylated haemoglobin ( $\mathrm{HbA1c}$ ) and measures of insulin resistance across a range of glucose tolerance. Scand J Clin Lab Invest. 2011;71(2):168-72.

87. Desport JC, Preux PM, Magy L, Boirie Y, Vallat JM, Beaufrère B, et al. Factors correlated with hypermetabolism in patients with amyotrophic lateral sclerosis. Am J Clin Nutr. 2001;74(3):328-34.

88. Desport JC, Torny F, Lacoste M, Preux PM, Couratier P. Hypermetabolism in ALS: correlations with clinical and paraclinical parameters. Neurodegener Dis. 2005;2(3-4):202-7.

89. Funalot B, Desport JC, Sturtz F, Camu W, Couratier P. High metabolic level in patients with familial amyotrophic lateral sclerosis. Amyotroph Lateral Scler. 2009;10(2):113-7.
90. Daulatzai MA. Cerebral hypoperfusion and glucose hypometabolism: key pathophysiological modulators promote neurodegeneration, cognitive impairment, and Alzheimer's disease. J Neurosci Res. 2017;95(4):943-72.

\section{Ready to submit your research? Choose BMC and benefit from:}

- fast, convenient online submission

- thorough peer review by experienced researchers in your field

- rapid publication on acceptance

- support for research data, including large and complex data types

- gold Open Access which fosters wider collaboration and increased citations

- maximum visibility for your research: over $100 \mathrm{M}$ website views per year

At BMC, research is always in progress.

Learn more biomedcentral.com/submissions 